\title{
Karakteristik Pektin Kulit Pisang Tongka Langit (Musa troglodytarum) Berdasarkan Variasi Waktu Ekstraksi
}

\author{
Characteristics of Pectin from Tongka Langit (Musa troglodytarum) Banana Peels on the \\ Various Extraction Times
}

\section{Priscillia Picauly*, Gilian Tetelepta}

Jurusan Teknologi Hasil Pertanian, Fakultas Pertanian Universitas Pattimura, Jl. Ir. M. Putuhena Kampus Poka Ambon 97233

*Penulis korespondensi: Priscillia Picauly, e-mail: priscilia_pic@yahoo.com

Tanggal submisi: 21 Maret 2020; Tanggal penerimaan: 27 April 2020

\begin{abstract}
Tongka langit banana peel is an organic waste that has not been widely used by the community and has a pectin content of about $10.41 \%$. Pectin extraction from banana peels should thus be done effectively to utilize waste. The objective of this research was to characterize the properties of pectin extracted from banana tongka langit peel with the different extraction times. A completely randomized experimental design with 3 level treatment extraction time of banana tongka langit peel, i.e., 1 hour, 1,5 hours, and 2 hours with three replicates was applied in this research. The properties evaluated, including equivalent weight, methoxyl content, galacturonate acid, esterification degree, yield, moisture content, and ash content. Result showed that equivalent weight $(757.88 \mathrm{mg}, 735.48 \mathrm{mg}$, and $699.8 \mathrm{mg})$, methoxyl content $(5.10 \%, 5.17 \%$, and $5.44 \%)$, galacturonate acid $(52.22 \%, 53.32 \%$, and $56.08 \%)$, esterification degree $(55.07 \%, 55.12 \%$, and $55.43 \%)$, moisture content $(9.99 \%, 9.90 \%$, and $9.85 \%)$, ash $(6.17 \%, 6.23 \%$, and $6.46 \%)$, and yield $(8.35 \%, 8.93 \%$, and $9.2 \%)$.
\end{abstract}

Keywords: banana tongka langit peel, pectin, extraction time

\begin{abstract}
ABSTRAK
Kulit pisang tongka langit merupakan limbah organik yang belum banyak dimanfaatkan oleh masyarakat dan memiliki kandungan pektin sebanyak 10,41\%. Ekstraksi pektin dari kulit pisang tongka langit harus dilakukan secara efektif dalam memanfaatkan limbah. Penelitian ini bertujuan untuk mengkarakterisasi pektin kulit pisang tongka langit berdasarkan waktu ekstraksi pektin yang berbeda. Penelitian ini menggunakan Rancangan Acak Lengkap yang terdiri dari tiga tingkat perlakuan waktu ekstraksi pektin kulit pisang tongka langit yaitu 1 jam, 1,5 jam, dan 2 jam dengan 3 kali ulangan. Pengamatan dilakukan terhadap berat ekuivalen, kadar metoksil, kadar asam galakturonat, derajat esterifikasi, rendemen, kadar air, dan kadar abu. Hasil penelitian menunjukkan nilai berat ekuivalen $(757,88 \% \mathrm{mg}, 735,48 \mathrm{mg}$, dan $699,80 \mathrm{mg})$, kadar metoksil $(5,10 \%, 5,17 \%$, dan $5,44 \%)$, kadar asam galakturonat $(52,22 \%, 53,32 \%$, dan $56,08 \%)$, nilai derajat esterifikasi $(55,07 \%, 55,12 \%$, dan 55,43\%), kadar air $(9,99 \%, 9,90 \%$, dan 9,85\%), kadar abu $(6,17 \%, 6,23 \%$, dan 6,46\%), dan rendemen $(8,35 \%, 8,93 \%$, dan $9,2 \%)$.
\end{abstract}

Kata kunci: kulit pisang tongka langit, pektin, waktu ekstraksi 


\section{PENDAHULUAN}

Maluku mempunyai salah satu jenis buah pisang lokal yang cukup khas dan berpotensi untuk dikembangkan yaitu pisang tongka langit (Musa troglodytarum L.). Pisang tongka langit dikonsumsi secara langsung sebagai buah segar atau diolah dengan cara dibakar, dikukus, dan direbus serta dapat dijadikan produk olahan seperti biskuit (Mailoa, 2013), bubur instan (Picauly dan Tetelepta, 2015), crackers (Picauly dan Tetelepta, 2016), brownies (Moniharapon et al., 2019), pati (Palijama et al., 2020) dan beberapa produk lainnya. Pemanfaatan daging buah pisang untuk diolah menjadi berbagai makanan akan menghasilkan limbah berupa kulit pisang. Menurut Tchobanoglous et al. (1993), berat limbah kulit pisang dapat memberikan sekitar $40 \%$ dari jumlah berat buah pisang. Kulit pisang tongka langit belum dimanfaatkan, hanya dibuang sebagai limbah organik atau digunakan sebagai makanan ternak. Kulit pisang akan memiliki nilai jual yang menguntungkan apabila diolah menjadi sesuatu yang bermanfaat. Menurut Happi et al. (2008), kulit pisang dapat dimanfaatkan sebagai sumber bahan pangan yang memiliki nilai tinggi seperti pektin.

Kulit pisang tongka langit berpotensi untuk menghasilkan senyawa pektin. Berdasarkan hasil penelitian terlihat kandungan pektin dalam kulit pisang tongka langit sebesar $10.41 \%$ (Sutapa et al., 2014). Pektin atau senyawa pektat adalah suatu polisakarida kompleks yang terdapat pada lamela tengah (middle lamella). Pektin merupakan asam poligalakturonat yang mengandung metil ester. Pektin tersusun atas molekul asam galakturonat yang berikatan dengan $\alpha$-(1,4)-glikosida sehingga membentuk asam poligalakturonat (Wang et al., 2007).

Pektin dapat digunakan secara luas sebagai komponen fungsional pada industri makanan. Hanya saja di Indonesia masih tergantung pada import pektin, sehingga pektin komersial memiliki harga yang cukup tinggi. Berdasarkan hal tersebut maka perlu dimanfaatkan sumber pektin yang ada seperti kulit pisang tongka langit.

Lamanya waktu ekstraksi dalam proses ekstraksi pektin, sangat mempengaruhi karakteristik pektin. Terdapat beberapa penelitian yang mengevaluasi pengaruh waktu ekstraksi pektin yang berbeda dari beberapa jenis kulit pisang antara lain pisang cavendish, pisang ambon kuning dan jenis lainnya (Happi et al., 2010; Oliveira et al., 2016; Qiu et al., 2010). Namun sampai saat ini belum ada penelitian yang mengevaluasi pengaruh waktu dalam proses ekstraksi pektin dari kulit pisang tongka langit.

Berdasarkan hal tersebut maka tujuan penelitian ini yaitu untuk mengkarakteristik pektin kulit pisang tongka langit berdasarkan waktu ekstraksi pektin yang berbeda.

\section{METODE PENELITIAN}

\section{Bahan}

Bahan untuk ekstraksi pektin kulit pisang tongka langit adalah kulit pisang tongka langit yang diambil dari buah segar pisang tongka langit yang diperoleh dari Negeri Soya, Kota Ambon, dan bahan kimia asam klorida ( $\mathrm{HCl}$ ) (Merck), dan etanol $96 \%\left(\mathrm{C}_{2} \mathrm{H}_{5} \mathrm{OH}\right)$ (Merck).

\section{Ekstraksi Pektin}

Ekstraksi pektin mengacu pada metode Ramdja et al. (2011) dengan modifikasi. Kulit buah pisang tongka langit yang telah dibersihkan sebanyak $20 \mathrm{~g}$ dikeringkan menggunakan pengering kabinet. Setelah kering, kulit pisang tersebut dihancurkan dengan crusher. Serbuk kulit pisang tongka langit ditambah pelarut asam klorida $(0,1 \mathrm{~N})$ sebanyak $500 \mathrm{~mL}$ dan diekstraksi pada suhu $90{ }^{\circ} \mathrm{C}$ selama waktu perlakuan (1, 1,5 dan 2 jam). Selanjutnya dilakukan penyaringan untuk memisahkan endapan dengan filtratnya. Fitrat pektin diendapkan dengan etanol 96\% (1:1). Pektin yang telah diendapkan, dipisahkan dari filtratnya dengan menggunakan kertas saring. Endapan dicuci dengan etanol $96 \%$. Hasil filtrasi dikeringkan menggunakan oven pada suhu $40^{\circ} \mathrm{C}$ selama 24 jam, dan selanjutnya dilakukan analisa karakterisasinya.

\section{Pengamatan}

Pengamatan yang akan dilakukan pada pektin kulit pisang tongka langit meliputi berat ekuivalen (Ranggana, 1997), kandungan metoksil (Ranggana, 1997), kadar asam galakturonat (Ranggana, 1997), derajat esterifikasi (Ranggana, 1997), kadar air (AOAC, 2012), kadar abu (AOAC, 2012), dan rendemen.

\section{Berat Ekuivalen}

Pektin sebanyak $0,5 \mathrm{~g}$ dibasahi dengan $5 \mathrm{~mL}$ etanol $96 \%$ dan dilarutkan dalam $100 \mathrm{~mL}$ akuades yang berisi $1 \mathrm{~g} \mathrm{NaCl}$. Pemberian garam digunakan untuk mempertajam titik akhir. Larutan hasil campuran tersebut dititrasi perlahan-lahan dengan 
$\mathrm{NaOH} 0,1 \mathrm{~N}$ dengan indikator fenol merah sampai terjadi perubahan menjadi merah kekuningan $(\mathrm{pH}$ $7,5)$ yang bertahan 30 detik. Indikator fenol merah memiliki $\mathrm{pH}$ 6,8-8,2. Titrasi dilakukan perlahan untuk menghindari deesterifikasi.

$$
\text { Berat ekuivalen }(\mathrm{mg})=\frac{\text { Berat sampel }(\mathrm{g}) \times 1000}{\text { Volume } \mathrm{NaOH}(\mathrm{mL}) \times \mathrm{N} \mathrm{NaOH}}
$$

\section{Kadar metoksil}

Larutan netral dari penentuan BE ditambah $25 \mathrm{~mL}$ larutan $\mathrm{NaOH} 0,25 \mathrm{~N}$ dan dikocok serta dibiarkan selama 30 menit dalam keadaan tertutup. Selanjutnya ditambahkan $25 \mathrm{~mL} \mathrm{HCl} \mathrm{0,25} \mathrm{N} \mathrm{dan}$ dititrasi dengan larutan $\mathrm{NaOH} 0,1 \mathrm{~N}$ dengan indikator fenol merah sampai titik akhir.

$$
\text { Kadar metoksil }(\%)=\frac{\text { Volume } \mathrm{NaOH} \times \mathrm{N} \mathrm{NaOH} \times 31}{\text { Berat sampel }(\mathrm{g})}
$$

\section{Kadar asam galakturonat}

Kadar galakturonat dihitung dari mek (miliekivalen) $\mathrm{NaOH}$ yang diperoleh dari penentuan berat ekuivalen dan kandungan metoksil.

Kadar asam galaturonat $(\%)=\frac{\operatorname{mek}(\mathrm{BE}+\mathrm{KM}) \times \mathrm{N} \mathrm{NaOH} \times 176 \times 100}{\text { Berat sampel }(\mathrm{mg})}$

\section{Derajat Esterifikasi}

Derajat esterifikasi dihitung dari kadar metoksil dan kadar galakturonat yang diperoleh.

$$
\text { Derajat esterifikasi }(\%)=\frac{\text { Kadar metoksil } \times 176 \times 100}{\text { Kadar galakturonat } \times 31}
$$

\section{Kadar Air}

Sampel sebanyak $5 \mathrm{~g}$ setelah cawan aluminium dikeringkan di dalam oven selama 15 menit lalu didinginkan dalam desikator. Cawan yang sudah berisi sampel dikeringkan pada oven (Memmert, Germany) suhu $105^{\circ} \mathrm{C}$ selama 3 jam. Cawan didinginkan kemudian ditimbang.

\section{Kadar Abu}

Keringkan cawan porselin kosong di dalam oven (Memmert, Germany) bersuhu $105^{\circ} \mathrm{C}$ selama 15 menit dan didinginkan dalam desikator. Cawan kemudian ditimbang dan dicatat beratnya. Sebanyak 1,5 g contoh ditimbang kemudian dipanaskan didalam tanur listrik (Vulcan A-550 Ney, AS) pada suhu maksimum $550^{\circ} \mathrm{C}$ sampai pengabuan sempurna. Cawan didinginkan di dalam desikator dan kemudian ditimbang.

\section{Rendemen}

Perhitungan rendemen dilakukan dengan menimbang pektin kering yang dihasilkan kemudian dibagi dengan berat bahan baku yang telah dikeringkan.

$$
\text { Rendemen }(\%)=\frac{\text { Berat pektin }(\mathrm{g})}{\text { Berat kering bahan baku }(\mathrm{g})} \times 100 \%
$$

\section{Rancangan Percobaan dan Analisis Statistik}

Penelitian ini menggunakan rancangan acak lengkap dengan tiga taraf perlakuan waktu ekstraksi pektin yaitu 1, 1,5, dan 2 jam. Masing-masing taraf perlakuan diulang sebanyak tiga kali. Analisis keragaman digunakan untuk menganalisis data yang diperoleh dan uji BNJ untuk uji beda rataan perlakuan dengan menggunakan software Minitab 17.

\section{HASIL DAN PEMBAHASAN}

\section{Berat Ekuivalen}

Berat ekuivalen pektin kulit pisang tongka langit berdasarkan waktu ekstraksi yaitu berturutturut sebesar 757,88 mg, 735,48 mg dan 699,8 mg. Untuk standar mutu IPPA (International Pectin Producers Association) (2002), berat ekuivalen pektin berkisar antara 600-800 mg, sehingga berat ekuivalen pektin kulit pisang tongka langit sudah memenuhi standar. Berat ekuivalen tertinggi pada pektin kulit pisang tongka langit yang diekstraksi selama 1 jam yaitu sebesar $757 \mathrm{mg}$ dan berbeda nyata dengan perlakuan lama ekstraksi selama 2 jam. Hasil penelitian menunjukkan bahwa semakin lama waktu ekstraksi pektin kulit pisang tongka langit maka nilai berat ekuivalen akan menurun. Hasil yang sama juga dikemukakan oleh Nadir dan Rismani (2018) yang menunjukkan kecenderungan semakin lamanya waktu ekstraksi menghasilkan berat ekuivalen pektin kulit pisang kapok akan semakin rendah. Hal ini desebabkan karena semakin lamanya waktu ekstraksi akan menyebabkan proses deesterifikasi pektin menjadi asam pektat. Proses deesterifikasi ini akan meningkatkan jumlah gugus asam bebas. Peningkatan jumlah gugus asam bebas inilah yang akan menurunkan berat ekuivalen. 
Tabel 1. Karakteristik pektin kulit pisang tongka langit berdasarkan lama waktu ekstraksi

\begin{tabular}{lcccl}
\hline \multirow{2}{*}{ Karakterisasi Pektin } & \multicolumn{3}{c}{$\begin{array}{c}\text { Perlakuan } \\
\text { Lama waktu ekstraksi (jam) }\end{array}$} & $\begin{array}{c}\text { Standar mutu IPPA } \\
\text { (International Pectin } \\
\text { Producers Association) }\end{array}$ \\
\cline { 2 - 4 } & \multicolumn{1}{c}{1} & 1,5 & 2 & \multicolumn{1}{c}{$2,800-800 \mathrm{mg}$} \\
Berat ekuivalen (mg) & $757,88 \mathrm{a} \pm 7,21$ & $735,48 \mathrm{a} \pm 3,92$ & $699,8 \mathrm{~b} \pm 18,4$ & \\
Kadar metoksil (\%) & $5,10 \mathrm{a} \pm 0,01$ & $5,17 \mathrm{ab} \pm 0,02$ & $5,44 \mathrm{~b} \pm 0,16$ & $<7 \%$ (metoksil rendah) \\
Kadar galakturonat (\%) & $52,22 \mathrm{a} \pm 0,30$ & $53,32 \mathrm{~b} \pm 0,27$ & $56,08 \mathrm{~b} \pm 1,60$ & Min 35\% \\
Derajat esterifikasi (\%) & $55,43 \mathrm{a} \pm 0,17$ & $55,12 \mathrm{ab} \pm 0,00$ & $55,07 \mathrm{~b} \pm 0,12$ & $>50 \%$ (pektin ester tinggi) \\
Kadar air (\%) & $9,99 \mathrm{a} \pm 0,00$ & $9,90 \mathrm{~b} \pm 0,00$ & $9,85 \mathrm{c} \pm 0,00$ & Maks 12\% \\
Kadar abu (\%) & $6,17 \mathrm{a} \pm 0,00$ & $6,23 \mathrm{a} \pm 0,03$ & $6,47 \mathrm{~b} \pm 0,02$ & Maks 10\% \\
Rendemen (\%) & $8,35 \mathrm{a} \pm 0,00$ & $8,93 \mathrm{~b} \pm 0,00$ & $9,2 \mathrm{c} \pm 0,00$ & \\
\hline
\end{tabular}

Keterangan: Notasi yang sama pada kolom yang sama menunjukkan tidak ada perbedaan yang nyata pada uji BNJ $(\alpha=$ $0,01)$.

\section{Kadar Metoksil}

Kadar metoksil pektin kulit pisang tongka langit berdasarkan waktu ekstraksi yaitu berturutturut sebesar 5,10\%, 5,17\%, dan 5,44\%. Pektin kulit pisang tongka langit yang dihasilkan pada penelitian ini kurang dari $7 \%$ sehingga termasuk pektin bermetoksil rendah menurut data standar mutu IPPA (International Pectin Producers Association) (2002). Semakin tinggi kadar metoksil dalam molekulnya maka akan semakin cepat menjadi gel. Menurut Goycoolea dan Adriana (2003) pektin disebut bermetoksil tinggi jika kadar metoksil sama dengan atau lebih dari $7 \%$, dan disebut bermetoksil rendah jika kadar metoksil kurang dari $7 \%$. Pektin yang memiliki kandungan metoksil rendah lebih menguntungkan karena pektin bermetoksil rendah dapat langsung diproduksi tanpa melalui proses demetilasi. Kadar metoksil tertinggi pektin kulit pisang tongka langit pada perlakuan lamanya ekstraksi selama 2 jam yaitu sebanyak $5,44 \%$ dan berbeda nyata dengan perlakuan lama ekstraksi pektin selama 1 jam.

Hasil penelitian menunjukkan bahwa semakin lama waktu ekstraksi pektin kulit pisang tongka langit maka nilai kadar metoksil akan semakin meningkat. Hal ini sesuai dengan hasil penelitian Tuhuloula et al. (2013) yang menunjukkan semakin lamanya waktu ekstraksi menghasilkan kadar metoksil yang semakin tinggi. Peningkatan nikai kadar metoksil ini sebabkan karena semakin lamanya waktu ekstraksi akan menyebabkan semakin meningkatnya gugus karboksil bebas yang teresterifikasi. Menurut Roikah et al. (2016) bahwa terjadi peningkatan kadar metoksil seiring peningkatan waktu ekstraksi disebabkan karena adanya gugus karboksil pada pektin dapat mengalami esterifikasi dengan metanol sehingga dapat meningkatkan kadar metoksil pektin tersebut.

\section{Kadar Asam Galakturonat}

Kadar asam galakturonat pektin kulit pisang tongka langit berdasarkan waktu ekstraksi yaitu berturut-turut sebesar $52,22 \%, 53,32 \%$, dan $56,08 \%$. Semakin tinggi kadar asam galakturonat pektin maka mutu pektin semakin tinggi. Kadar asam galakturonat berdasarkan standar mutu pektin yang ditetapkan oleh IPPA (2002), yaitu kadar galakturonat minimal sebesar 35\%. Untuk itu pektin kulit pisang tongka langit yang dihasilkan pada penelitian ini sesuai dengan standar mutu pektin. Kadar asam galakturonat yang tertinggi pada pektin kulit pisang tongka langit dengan lama waktu ekstraksi selama 2 jam yaitu sebesar $56,08 \%$ dan berbeda nyata dengan perlakuan waktu ekstraksi 1 jam.

Hasil penelitian menunjukkan bahwa semakin lama waktu ekstraksi pektin kulit pisang tongka langit maka kadar asam galakturonat pektin kulit pisang tongka langit akan semakin meningkat. Hal ini sesuai dengan hasil penelitian Kamble et al. (2017) yang menunjukkan ekstraksi pektin selama 2 jam menghasilkan kadar asam galakturonat sebesar $56,67 \%$ dan semakin lama waktu ekstraksi menghasilkan kadar asam galakturonat yang semakin tinggi. Peningkatan kadar asam galakturonat ini disebabkan karena meningkatnya reaksi hidrolisis protopektin menjadi pektin yang komponen dasarnya adalah asam D-galakturonat sehingga meningkat asam galakturonat.

\section{Derajat Esterifikasi}

Derajat esterifikasi pektin kulit pisang tongka langit berdasarkan waktu ekstraksi yaitu berturut- 
turut sebesar 55,07\%, 55,12\%, dan 55,43\%. Menurut standar mutu pektin yang ditetapkan IPPA (2002), pektin yang dihasilkan pada penelitian ini termasuk pektin ester tinggi karena memiliki derajat esterifikasi yang lebih dari 50\%. Nilai derajat esterifikasi pektin kulit pisang tongka langit tertinggi pada perlakuan lama ekstraksi 2 jam yaitu sebesar $55,43 \%$ yang berbeda nyata dengan lama waktu ekstrasi 1 jam.

Hasil penelitian menunjukkan bahwa semakin lama waktu ekstraksi pektin kulit pisang tongka langit maka nilai derajat esterifikasi pektin kulit pisang tongka langit akan semakin meningkat. Hal ini sesuai dengan hasil penelitian Kamble et al. (2017) yang menunjukkan semakin lamanya waktu ekstraksi menghasilkan derajat esterifikasi yang semakin tinggi. Derajat esterifikasi yang cenderung meningkat seiring dengan bertambahnya waktu dikarenakan ikatan glikosidik gugus metil ester dari pektin cenderung terhidrolisis menghasilkan asam galakturonat. Jika ekstraksi dilakukan terlalu lama, pektin akan berubah menjadi asam pektat yang asam galakturonatnya bebas dari gugus metil ester. Jumlah gugus metil ester menunjukkan jumlah gugus karboksil yang tidak teresterifikasi atau derajat esterifikasi.

\section{Kadar Air}

Kadar air pektin kulit pisang tongka langit berdasarkan waktu ekstraksi yaitu berturut-turut sebesar 9,99\%, 9,90\%, dan 9,85\%. Kadar air tertinggi pada pektin kulit pisang tongka langit dengan perlakuan waktu lamanya ekstraksi 1 jam yaitu sebesar 9,99\% yang berbeda nyata dengan lama ekstraksi 1 dan 1,5 jam. Menurut data standar mutu IPPA (2002), kadar air maksimal sebesar $12 \%$, sehingga pektin kulit pisang tongka langit memenuhi standar mutu.

Hasil penelitian menunjukkan bahwa semakin lama waktu ekstraksi pektin kulit pisang tongka langit maka kadar air pektin kulit pisang tongka langit akan semakin menurun. Hal ini sesuai dengan hasil penelitian Roikah et al. (2016) bahwa semakin lama waktu ekstraksi pektin belimbing wuluh maka kadar air semakin menurun. Penurunan kadar air ini disebabkan karena air akan menguap selama proses ekstraksi sehingga dapat menurunkan kadar air bahan pangan atau pektin kulit pisang tongka langit. Menurut Prasetyowati dan Pesantri (2009) semakin kecil kadar air maka akan semakin baik kualitas pektin.

\section{Kadar Abu}

Kadar abu pektin kulit pisang tongka langit berdasarkan waktu ekstraksi yaitu berturut-turut sebesar 6,17\%, 6,23\%, dan 6,46\%. Menurut data standar mutu IPPA (2002), kadar abu maksimal sebesar $10 \%$, sehingga pektin kulit pisang tongka langit memenuhi standar mutu. Kadar abu tertinggi pektin kulit pisang tongka langit terdapat pada perlakuan lama ekstraksi selama 2 jam yaitu sebesar $6,46 \%$ yang berbeda nyata dengan perlakuan lama ekstraksi 1 dan 1,5 jam. Semakin tinggi tingkat kemurnian pektin, maka kadar abu dalam pektin semakin rendah. Sehingga tingkat kemurnian pektin pisang tongka langit akan rendah seiiring lamanya waktu ekstraksi pektin.

Kadar abu pektin kulit pisang tongka langit menunjukkan semakin lama waktu yang digunakan untuk ekstraksi maka semakin tinggi nilai kadar abu. Hal ini sesuai dengan hasil penelitian Roikah et al. (2016) bahwa semakin lama waktu ekstraksi pektin belimbing wuluh maka kadar abu semakin menurun. Penurunan kadar abu ini disebabkan karena adanya pemanasan dalam asam dengan waktu ekstraksi yang lama maka akan meningkatkan reaksi hidrolisis protopektin yang akan berubah menjadi pektin yang akan banyak mengendap. Protopektin dalam buah-buahan berada dalam bentuk kalsium dan magnesium pektat dan jika dicampurkan dengan asam akan mengakibatkan terhidrolisisnya pektin dari ikatan kalsium dan magnesium. Komponen tersebut akan banyak terlarut dalam larutan ekstrak dan ikut mengendap jika reaksi hidrolisis protopektin ditingkatkan, sehingga kadar abu pektin akan tinggi.

\section{Rendemen}

Rendemen pektin kulit pisang tongka langit berdasarkan waktu ekstraksi yaitu berturut-turut sebesar 8,35\%, 8,93\%, dan 9,20\%. Rendemen pektin kulit pisang tongka langit tertinggi terdapat pada perlakuan lama ekstraksi 2 jam yaitu sebesar $9,2 \%$ yang berbeda nyata dengan perlakuan waktu lama ekstraksi 1 dan 1,5 jam. Hasil penelitian menunjukkan bahwa semakin lama waktu ekstraksi pektin kulit pisang tongka langit maka rendemen pektin kulit pisang tongka langit akan semakin meningkat. Hal ini sesuai dengan hasil penelitian Febriyanti (2018) menunjukkan kecenderungan semakin lamanya waktu ekstraksi yang digunakan akan menghasilkan rendemen yang semakin tinggi. Menurut Prasetyowati dan Pesantri (2009) bahwa semakin tinggi waktu ekstraksi maka semakin 
tinggi rendemen pektin. Hal ini disebabkan ion hidrogen yang yang mensubstitusi kalsium dan magnesium dari protopektin yang terhidrolisis akan menyebabkan rusaknya molekul pada ikatan rantai galakturonat menjadi terlepas. Menurut Evi et al. (2013) waktu ekstraksi pektin berbanding lurus dengan jumlah protopektin yang berubah menjadi pektin, tetapi pada waktu tertentu pektin dapat terdegradasi menjadi asam pektat.

\section{KESIMPULAN}

Berdasarkan hasil penelitian maka disimpulkan bahwa karakteristik pektin kulit pisang tongka langit berdasarkan lama waktu ekstraksi 1, 1,5, dan 2 jam menghasilkan berat ekuivalen $(757,88$, 735,48 , dan 699,80), kadar metoksil $(5,10,5,17$, dan $5,44 \%)$, asam galakturonat $(52,22,53,32$, dan $56,08 \%)$, derajat esterifikasi $(55,07,55,12$, dan $55,43 \%)$, kadar air $(9,99,9,90$, dan 9,85\%), kadar abu $(6,17,6,23$, dan $6,46 \%)$ dan rendemen $(8,35$, $8,93$, dan $9,2 \%)$.

\section{DAFTAR PUSTAKA}

AOAC. 2012. Association of Official Analytical Chemistry, Washington D.C. Official Method of Analysis.

Evi, Z.N., N. Yuli, dan Rusdiansjah. 2013. Pengaruh suhu dan waktu terhadap hasil ekstraksi pektin dari kulit buah nanas. Simposium Nasional RAPI XII. FT UMS. K 3943.

Febriyanti, Y., A.R. Razak, dan N.K. Sumarni. 2018. Ekstraksi dan karakterisasi pektin dari kulit buah kluwih. Jurnal Kovalen 4: 60-73.

Goycoolea, F.M. and A. Cárdenas. 2003. Pectins from Opuntia spp.: A short review. Journal of the Professional Association for Cactus Development 5: 17-29.

Happi, E.T., S.N. Ronkart, C. Robert, B. Wathelet, and M. Paquot. 2008. Characterisation of pectins extracted from banana peels (Musa AAA) under different conditions using an experimental design. Food Chemistry 108: 463-471. DOI: 10.1016/j.foodchem.2007.10.078

IPPA. 2002. What Is Pectin. International Pectin Producers Association. https://ippa.info/labelling-safety- regulationof-pectin/. Accessed $12^{\text {th }}$ January 2020.

Kamble, P.B., S. Gawande, and T.S. Patil. 2017. Extraction of pectin from unripe banana peel. International Research Journal of
Engineering and Technology 4: 2259-2264.

Mailoa, M. 2013. Pengembangan pisang Tongka Langit (Musa troglodytarum) menjadi biskuit. Ekosains 1: 6-13.

Moniharapon, E., L. Lelmalaya, dan P. Picauly. 2019. Kajian sifat kimia dan organoleptik brownies pisang tongka langit. Agritekno 8: 60-63. DOI: 10.30598/jagritekno.2018.7.2.60

Nadir, M, and E. I. Risfani. 2018. Pengaruh waktu terhadap ekstraksi pektin dari kulit pisang kepok dengan metode microwafe assisted extraction (MAE). Prosiding Seminar Hasil Penelitian (SNP2M). pp 92-98.

Oliveira, T.I.S., M.F. Rosa, F.L. Cavalcante, P.H.F. Pereira, G.K. Moates, N. Wellner, S.E. Mazzetto, K.W. Waldron, and H.M.C. Azeredo. 2016. Optimization of pectin extraction from banana peels with citric acid by using response surface methodology. Food Chemistry 198: 113-118. DOI: 10.1016/j.foodchem.2015.08.080

Picauly, P. and G. Tetelepta. 2015. Karakteristik kimia bubur instan tersubtitusi tepung pisang tongka langit. Agroforestri 9: 122-126.

Palijama, S., M. Singkery, R. Breemer, and F.J. Polnaya. 2020. Isolation and characteristics of Musa troglodytarum L. starch at different maturity stage. Journal of Physics: Conference Series 1463: 012015. DOI: 10.1088/1742-6596/1463/1/012015

Picauly, P. dan G. Tetelepta. 2016. Uji organoleptik crackers pisang tongka langit. Agritekno 5: 53-57. DOI: 10.30598/jagritekno.2016.5.2.53

Prasetyowati, S.K.P. dan H. Pesantri. 2009. Ekstraksi pektin dari kulit mangga. Jurnal Teknik Kimia 16: 42-49.

Qiu, L.P., G.L. Zhao, H. Wu, L. Jiang, X.F. Li, and J.J. Liu. 2010. Investigation of combined effects of independent variables on extraction of pectin from banana peel using response surface methodology. Carbohydrate Polymers 80: 326-331. DOI: 10.1016/j.carbpol.2010.01.018

Ramdja, A. F., D. P. Adhitya, dan R. Rusman. Ekstraksi pektin dari kulit pisang kepok dengan pelarut asam klorida dan asam asetat. Jurnal Teknik Kimia 17: 28-37.

Ranggana, S. 1997. Handbook of Analysis and Quality Control for Fruit and vegetable Products Second Editions. Tata McGrawHill. Publishing Company Limited: New Delhi

Roikah, S., W.D.P. Rengga, Latifah, dan E. 
Kusumastuti. 2016. Ektraksi dan karakterisasi pektin dari belimbing wuluh (Averhoa bilimbi L). Jurnal Bahan Alam Terbarukan 5: 29-36. DOI: 10.15294/jbat.v5i1.5432

Sutapa, I.W., V.P.D. Siahay, dan M.F.J.D.P. Tanasale. 2014. Adsorpsi $\mathrm{Cu}^{2+}$ pada pektin dari kulit pisang Tongka Langit (Musa speices Van Balbisiana). Indonesian Journal of Chemical Research 1: 72-77.

Tchobanoglous, G., H. Theisen, and S.A. Vigil. 1993. Integrated Solid Waste Management: Engineering Principles and Management
Issues. McGraw-Hill. Michigan.

Tuhuloula, A., L. Budiyarti, and E.N. Fitriana. 2013. Karakterisasi pektin dengan memanfaatkan limbah kulit pisang menggunakan metode akstraksi. Konversi 2: 21-27.

Wang, S., F. Chen, J. Wu, Z. Wang, X. Liao, and X. Hu. 2007. Optimization of pectin extraction assisted by microwave from apple pomace using response surface methodology. Journal of Food Engineering 78: 693-700. DOI: 10.1016/j.jfoodeng.2005.11.008 